\title{
Accuracy of face castings employing thermoplastic custom trays for facial molding
}

\author{
Kaue Campos Pavanello', Priscila Galzo Marafon', Beatriz Silva Câmara Mattos ${ }^{1}$ \\ 'Department of Maxillofacial Surgery, Prosthesis and Traumatology, School of Dentistry, University of São Paulo, São Paulo, Brazil
}

Received for publication: April 05, 2013 Accepted: July 31, 2013

Correspondence to: Beatriz Silva Câmara Mattos Faculdade de Odontologia da Universidade de São Paulo Avenida Lineu Prestes 2227, CEP: 05508-000 Cidade Universitária, São Paulo, SP, Brasil Phone/fax: +55 1130917879

E-mail: bscmatto@usp.br

\begin{abstract}
Aim: To evaluate the dimensional stability of a new facial molding technique using thermoplastic custom molding tray. Methods: The designs established demarcation of facial anthropometrics landmarks, making linear measurements with a digital caliper. Facial molding was carried out using thermoplastic custom trays, constructing a facial plaster cast with the anthropometric landmarks already transferred by measuring the linear dimensions on the plaster cast and statistical analysis. Results: All linear measurements in the palpebral and labial regions presented statistically significant distortions. Only one of the linear measurements from the orbital region did not demonstrate any significant distortion. The nasal region presented the least amount of distortion. Conclusions: Although statistically significant, distortions were due to the method of breathing and were considered to be clinically irrelevant. The reduction in the working time, the comfort provided to the patient and the dimensional accuracy of the plaster cast obtained by the facial molding technique using custom perforated molding tray suggest that this technique should be employed for making facial prostheses.
\end{abstract}

Keywords: facial prosthesis, molding material, anthropometrics.

\section{Introduction}

In most instances, facial prosthesis represents the only possibility for rehabilitation of facial mutilation resulting from trauma or cancer surgery, with immediate esthetic and functional results that will enhance the patient's quality of life. It is important to obtain a mold casting of the defective area, the morphology of the surrounding tissues, as well as the corresponding unaffected side, in order to sculpt the prostheses or, as more recently used, to adapt a wax prototype before ascertain its adjustment on the patient's face. Ariani et al. ${ }^{1}$ (2013), reviewing the techniques and materials used to rehabilitate maxillofacial defects, observed that it has not yet been described in the literature a fully digital workflow for scanning, designing, and fabricating maxillofacial prostheses to be placed directly onto the patient's defect, without plaster nor wax casts.

Low viscosity and good elastic recovery are important for the accurate facial molding and consequently of the final plaster cast. Additional amount of cold water provides a smooth fluid mix with a delayed set $^{2}$. During the conventional facial impression technique an initial layer of irreversible hydrocolloid is spread over the face and when it is set, a plaster layer is applied to act as reinforcement to the initial impression $^{3}$. This technique is time consuming and uncomfortable for the patient. It also requires too much material, resulting in excessive bulk and weight, which may distort the soft facial tissues and the dimensional stability of the irreversible hydrocolloid may be jeopardized by exothermic reaction during the plaster setting. 
The addition of two to eight drops of sodium phosphate increases the setting time, providing the professional an extended working time with no change in the elastic recovery of the irreversible hydrocoloid ${ }^{4}$. However, the significant amount of plaster required to provide rigidity for backing the impression material may deform the soft facial tissues and the final weight of the mold must be controlled by the professional in order to avoid distortion of the cast. Positioning the face in a vertical plane reduces the gravitational effect and ensures correct muscle toning, but complicates the contention of material in the area to be molded $^{5}$. The requirements for an ideal face impression material include the ability to record the defect, the adjacent structures and undercuts with minimal distortion, and to prevent soft tissue deformation by weight of the material. The supine position allows greater gravitational interference on the facial tissues, leading to deformation as a result of the excessive weight of the molding material ${ }^{6}$. Care should be taken when using conventional impression techniques, since the final weight of the plaster material may eventually deform the impression of a large facial $\mathrm{area}^{7}$. The impression material must have low viscosity and good elasticity in order to accomplish these aspects ${ }^{3}$.

Specific clinical situations, such as tissue movement during function, may require a preliminary conventional facial impression with irreversible hydrocolloid and then a customized acrylic tray with tissue-conditioning material may be used to produce a functional impression of the moveable areas. Low- and high-viscosity polyvinyl siloxane reduces the impression material's weight on the soft tissue and presents dimensional stability and high tear strength when compared to irreversible hydrocolloid. This material has been used to duplicate the defect site, where severe undercuts were blocked out using modeling wax of a previous facial plaster cast obtained from an irreversible hydrocolloid moulage ${ }^{8}$ Twopiece impression procedure is necessary when there are impression posts placed onto the implant abutments. The impression of the basal tissues of the defect area may be performed using medium-body polyether material and then the impression of the entire face is made with polyvinyl siloxane impression material ${ }^{9}$. However, extra-oral impressions require excessive material and its high cost is a disadvantage.

Facial impressions made with a thermoplastic custom tray and irreversible hydrocolloid proved to be effective in conventional situations. The tray is lightweight, which reduces the possibility of soft tissue displacement during the impression and can be disinfected, which allows storage for future use. It was observed that the irreversible hydrocolloid moldings and the perforated trays produced the same level of dimensional accuracy along the length and breadth of the dental $\operatorname{arch}^{10}$.

Modern computer technology for capturing threedimensional digital facial images and for constructing prototypes using the $\mathrm{CAD} / \mathrm{CAM}$ system introduces a new direction for obtaining facial casts. Plaster casts and molds created by capturing three-dimensional digital images proved to be statistically equivalent ${ }^{11}$. The distortion from the use of irreversible hydrocolloid was assessed by comparing data gathered from digitalization by scanning the patient's face and results obtained from the respective plaster mold produced by using the molding technique. The main deviations were found in the regions of the lips, nose, cheeks and the whole region covered by the lower third of face ${ }^{12}$. Facial casts made of plaster, obtained from conventional impression with irreversible hydrocolloid proved to have good reproducibility, enabling laboratorial adaptation of a prototype before the clinical first adjustment ${ }^{13}$.

Nevertheless, conventional facial molding techniques demand excessive time and discomfort for the patient, obliging the technician to maintain a control over the possibility of facial tissue distortion. This study proposes and assesses the dimensional accuracy of the facial molding technique utilizing irreversible hydrocolloid and a thermoplastic custom tray.

\section{Material and methods}

The study group comprised 15 adult volunteers, over 18 years of age and from both genders, following approval by the Ethics Committee, School of Dentistry, University of São Paulo - 204/2008. The volunteers were placed in dental chairs and the anthropometric landmarks were marked using a black dermatographic pencil - Koh-I-Noor, no. 3260-5, according to Farkas ${ }^{14}$. The anthropometric landmarks g, sn and $1 \mathrm{~s}$, located on the facial median line, were established in the first moment. The other landmarks were bilateral; being marked on both right and left hemi-faces. The anthropometric landmarks were grouped in regions as follows:

1. orbital region: $\mathrm{g}$ - en; $\mathrm{g}$ - ex; $\mathrm{g}$ - os; $\mathrm{g}$ - sci; sci - os

2. palpebral region: en - ex; en - ps; ex - os

3. nasal region: or - prn; or $-\mathrm{al}$; or $-\mathrm{sn}$; $\mathrm{ac}-\mathrm{ac}$; ac $-\mathrm{al}$

4. labial region: $\mathrm{cph}-\mathrm{cph}$; sn - cph; $1 \mathrm{~s}-\mathrm{sn}$

All the linear measurements were recorded for both right and left hemi-faces as well as the $1 \mathrm{~s}$ - sn measures, which are central to the face and the ac - ac and cph - cph measures, which consisted of isolated landmarks.

Data were collected with a digital caliper $\left(\mathrm{CD}-6^{\prime \prime} \mathrm{CX}\right.$ 'B; Mitutoyo Sul Americana Ltda., Suzano, SP, Brazil) by a single examiner and the data were registered in millimeters. For assessing the intra-examiner variability, two separate data collections were made from the faces of 10 individuals, with a 30 min interval between the first and second collection. The data were submitted to statistical analysis Cronbach's alpha $(\mathrm{p} \leq 0.05)$.

The custom molding was made with perforated Aquaplast $^{\circledR}$ (Patterson Medical Holdings, Inc., Bolingbrook, IL, USA) 1.6-mm-thick thermoplastic strips with moderate resistance to stretching, good adaptability and 100\% elastic memory ${ }^{15}$. Plasticization occurred at $70^{\circ} \mathrm{C}$ inside a plastifying tray, then it was slowly cooled and applied to the individual's face, according to the following limits: lower - upper lip; lateral - in front of the tragus; upper - a horizontal line through the glabella (Figure 1). After making the thermoplastic tray, the anthropometric points were marked and the linear measurements made. 


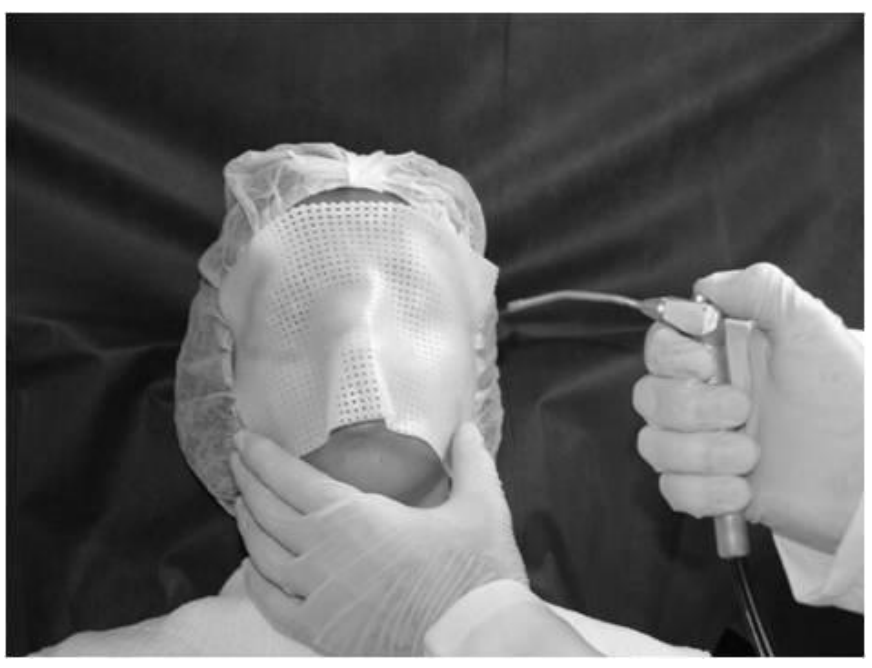

Fig. 1 - Thermoplastic material being cooled on the face.

The volunteers were seated in a dental chair, with normal axial relaxation and reclined $30^{\circ}$ to the horizontal plane. The nasal openings were occluded with humid sterile cotton wool, soaked in physiological saline solution, to prevent penetration of the molding material into the nose. Ventilation was maintained with oral breathing, by introducing a spacer, $1.0 \mathrm{~cm}$ thick, previously fixed to a sheet of rose wax no. 7 (Epoxiglass Ind. e Com. de Produtos Químicos Ltda., Diadema, SP, Brazil), between the anterior teeth, in a way to ensure oral breathing and restrain any run-down of the irreversible hydrocolloid (Jeltrate Type II; Dentisply Ind. e Comércio Ltda., Petrópolis, RJ, Brazil). The material was prepared in the water/powder proportion of $1.5 / 1$, a consistency more fluid than the one recommended by the manufacturer, to allow greater fluidity and a better flow of the material ${ }^{16}$ (Figure 2).

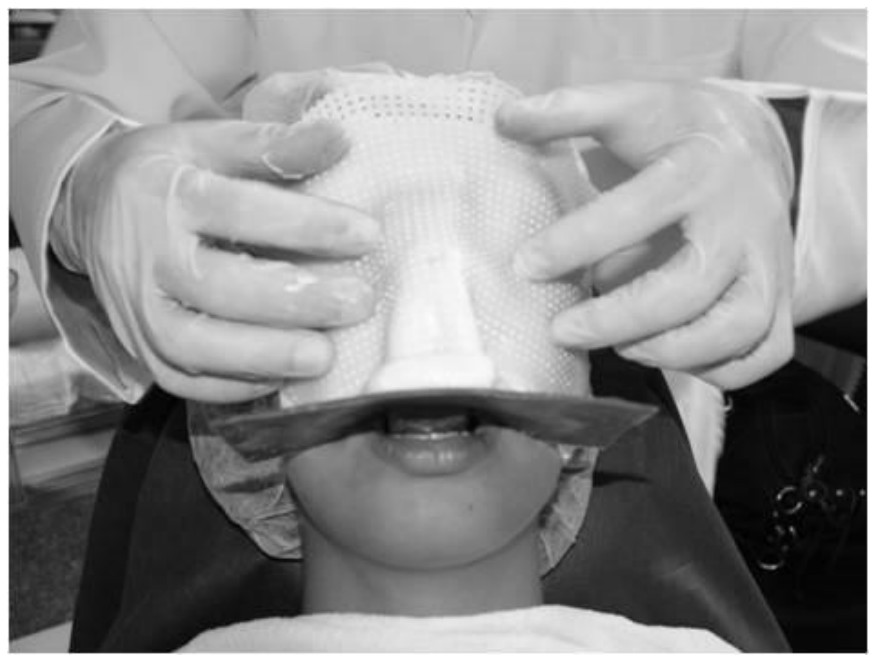

Fig. 2 - Facial molding with thermoplastic custom tray; mouth breathing.

The landmarks marked on the face were automatically transferred to the molding material in direct contact with the skin, by black pigment absorption and could be identified on the inner surface of the mold. These points were highlighted with a dermatographic pen before immediately proceeding to make the plaster cast using Plaster Rock Type III (Asfer tipo III ${ }^{\mathrm{TM}}$, Asfer Ind. Química Ltda., São Caetano do Sul, SP, Brazil) to avoid any deformation ${ }^{17}$. In the same way, these points were transferred to the plaster in contact with the ink, becoming evident on the outer surface of the plaster cast.

The same linear measurements, which were registered on the faces of the volunteers, were now taken from the facial casts. The statistical analysis Wilcoxon signed-rank test $(\mathrm{p} \leq 0.05)$ was set for evaluating the dimensional acuity of the casts resulting from the facial molding technique employing thermoplastic custom trays.

\section{Results}

The reliability of the values collected by the same technician from the faces of the 10 volunteers, maintaining an interval of $30 \mathrm{~min}$ between the two data collections, was carried out by statistical analysis Conbrach's alpha $(\mathrm{p} \leq 0.05)$, demonstrating internal consistency of the sample, with a high level of reliability. The statistical analysis of the data, using Wilcoxon signed-rank test $(\mathrm{p} \leq 0.05)$, for assessing the accuracy of the facial cast obtained by using thermoplastic custom trays, is presented according to the facial regions, considering first the right and then the left side.

All the linear measurements obtained from the orbital region of the face and from the plaster cast demonstrated significant statistical difference, except for the sci-ps measurement, on the left side (Table 1). The measurements obtained from palpebral region showed statistically significant difference on both left and right sides (Table 2). The nasal region showed no significant difference for the or-prn and

Table 1 - Orbital region - Wilcoxon signed-rank test.

\begin{tabular}{cccccc}
\hline Measurement & Variable & $\mathrm{N}^{*}$ & Mean & SD & Sig.(p) \\
g-en & ODF & 15 & 28.75 & 1.69 & 0.001 \\
& ODM & 15 & 29.67 & 1.89 & \\
g-ex & ODF & 15 & 57.82 & 2.70 & 0.001 \\
g-os & ODM & 15 & 59.11 & 3.29 & \\
& ODF & 15 & 35.69 & 3.61 & 0.006 \\
g-sci & ODM & 15 & 36.49 & 4.01 & \\
& ODF & 15 & 44.53 & 4.53 & 0.008 \\
sci-ps & ODM & 15 & 45.36 & 5.14 & \\
& ODF & 15 & 20.46 & 3.05 & 0.012 \\
g-en & ODM & 15 & 21.30 & 2.98 & \\
& OEF & 15 & 28.71 & 1.72 & 0.002 \\
g-ex & OEM & 15 & 29.33 & 1.73 & \\
& OEF & 15 & 57.96 & 3.04 & 0.001 \\
g-os & OEM & 15 & 59.45 & 3.52 & \\
& OEF & 15 & 37.62 & 4.16 & 0.001 \\
g-sci & OEM & 15 & 38.36 & 4.41 & \\
& OEF & 15 & 45.09 & 2.87 & 0.015 \\
sci-ps & OEM & 15 & 44.22 & 5.48 & \\
& OEF & 15 & 20.95 & 3.26 & 0.112 \\
\hline \multirow{2}{*}{ OEM } & 15 & 20.87 & 4.08 & \\
& OEM & & & &
\end{tabular}

$p \leq 0.05$. ${ }^{*}$ number of cases. 
Table 2 - Palpebral region - Wilcoxon signed-rank test.

\begin{tabular}{lccccc}
\hline Measurement & Variable & $\mathbf{N}^{*}$ & Mean & SD & Sig. $(\mathbf{p})$ \\
\hline en-ex & PFD & 15 & 35.02 & 2.18 & 0.002 \\
& PMD & 15 & 35.87 & 2.51 & \\
en-ps & PFD & 15 & 22.68 & 1.74 & 0.027 \\
& PMD & 15 & 23.15 & 1.58 & \\
ex-ps & PFD & 15 & 23.33 & 2.27 & 0.041 \\
& PMD & 15 & 23.60 & 2.49 & \\
en-ex & PFE & 15 & 34.82 & 2.75 & 0.005 \\
& PME & 15 & 35.31 & 2.95 & \\
en-ps & PFE & 15 & 22.02 & 3.15 & 0.001 \\
& PME & 15 & 24.43 & 5.09 & \\
ex-ps & PFE & 15 & 22.51 & 1.73 & 0.012 \\
& PME & 15 & 23.03 & 1.97 & \\
\hline \multirow{4}{*}{0.05.} & & & & & \\
& Cas. & & &
\end{tabular}

$p \leq 0.05$. ${ }^{*}$ number of cases.

Table 3 - Nasal region - Wilcoxon signed-rank test.

\begin{tabular}{cccccc}
\hline Measurement & Variable & $\mathbf{N}^{*}$ & Mean & SD & Sig. $\mathbf{p})$ \\
or-prn & NFD & 15 & 54.03 & 3.82 & 0.256 \\
& NMD & 15 & 54.34 & 4.14 & \\
or-al & NFD & 15 & 32.46 & 3.78 & 0.041 \\
& NMD & 15 & 33.50 & 2.37 & \\
or-sn & NFD & 15 & 51.05 & 3.43 & 0.041 \\
& NMD & 15 & 51.69 & 3.48 & \\
ac-ac & NF & 15 & 29.34 & 4.19 & 0.003 \\
& NM & 15 & 29.95 & 4.32 & \\
ac-al & NFD & 15 & 10.84 & 1.49 & 0.268 \\
& NMD & 15 & 10.99 & 1.39 & \\
or-prn & NFE & 15 & 55.63 & 4.12 & 0.061 \\
& NME & 15 & 56.02 & 3.99 & \\
or-al & NFE & 15 & 33.07 & 2.51 & 0.009 \\
& NME & 15 & 33.52 & 2.67 & \\
or-sn & NFE & 15 & 51.72 & 3.38 & 0.069 \\
& NME & 15 & 52.13 & 3.22 & \\
ac-al & NFE & 15 & 10.16 & 1.63 & 0.017 \\
& NME & 15 & 10.34 & 1.55 & \\
\hline
\end{tabular}

$p \leq 0.05 .{ }^{*}$ number of cases.

Table 4 - Labial region - Wilcoxon signed-rank test.

\begin{tabular}{lccccc}
\hline Measurement & Variable & $\mathbf{N}^{*}$ & Mean & SD & Sig.(p) \\
\multirow{3}{*}{ cph-cph } & LFD & 15 & 12.52 & 2.64 & 0.001 \\
\multirow{3}{*}{ sn-cph } & LMD & 15 & 13.06 & 2.60 & \\
& LFD & 15 & 13.65 & 1.89 & 0.001 \\
Is-sn & LMD & 15 & 14.30 & 1.93 & \\
& LFD & 15 & 14.09 & 2.01 & 0.003 \\
sn-cph & LMD & 15 & 14.65 & 2.20 & \\
\hline
\end{tabular}

$p \leq 0.05$. *number of cases.

ac-al measurements on the right side, as well as for the orprn and or-sn measurements on the left side (Table 3). The analysis of measurements obtained from the labial region of the face and from the facial cast demonstrated significant difference for all evaluated measurements (Table 4).

\section{Discussion}

Strategies in handling irreversible hydrocolloid are used in order to increase the working time and the viscosity of the material during the performance of facial molding. Therefore, the deliberate increase of the water to powder ratio to $1.5 / 1$, corresponds to $27 \mathrm{ml}$ of water for every $7 \mathrm{~g}$ of irreversible hydrocolloid powder ${ }^{16}$, resulting in an increase in the working time and the viscosity of the material without compromising its elasticity ${ }^{3}$. A more fluid molding material will present greater viscosity and diminish compression during the act of molding. This reduction in compression will minimize the amount of displacement suffered by the soft facial tissues, providing greater precision to the mold.

The correct positioning of the patient is also a significant factor for achieving proper impression fidelity, as a large area leads to greater volume of material and, consequently, a greater weight and possibility of deforming the soft facial tissues $^{6}$. The supine position allows greater gravitational interference on the facial tissues, leading to deformation as a result of the excessive weight of the molding material ${ }^{6}$. The position of the face at $30^{\circ}$ in relation to the horizontal plane was employed in this study in order to compensate the distorting effects mentioned above and allows greater control of the run-off of the molding material.

The use of a perforated molding and a uniform layer of irreversible hydrocolloid with a more fluid consistency minimizes the displacement of facial tissues and enables the perforations to mechanically retain the molding material ${ }^{3}$. These observations confirmed the advantages of using a perforated molding tray for performing facial moldings.

When marking the area to be molded in this study, the use of nasal tubes was discarded as ventilation was maintained by placing a strip of rose wax between the anterior teeth, which was attached to a rose wax laminate adapted to the contours of the lip in order to contain any possible runoff of the molding material. Claustrophobia and other sensations created by the contact of molding material on the face make it imperative that the individual is well oriented in order not to contract the mimic muscles. However, the fact that all linear measurements from the orbital region presented statistical differences, except for the left side scips measurement, suggests that peri-orbital muscular contraction did occur during the molding. Similarly, the palpebral region presented significant differences between the linear measurements obtained from the face and the facial cast, indicating that possible muscular contractions did occur.

The nasal region presented the greatest dimensional stability, with four measurements demonstrating statistical similarities. The use of nasal tubes is liable to create deformations around the nasal wings, where the nasal apex and the sub-nasal regions tend to present the greatest distortions ${ }^{12}$. In this study, the use of oral respiration may have avoided tissue deformation, preserving the linear measures and providing greater accuracy in the nasal region despite the fact that this region is not supported by underlying bone tissue. 
All linear measurements obtained from the labial region demonstrated significant difference. This fact may have resulted from deformities provoked by placing a strip of wax in the anterior maxillary region and confirms previous observations that in the case of oral respiration the upper lip is subjected to the greatest distortions ${ }^{12}$. It should be reminded that the ventilation system interferes in the accuracy of the final cast and, in a clinical situation, the professional should choose for nasal or oral breathing, depending on the area of the facial injury.

The perforated thermoplastic custom trays and irreversible hydrocolloid material technique for facial molding evaluated in this study confirmed the importance of minimizing the factors that interfere in the accuracy of the final cast: the position of the patient's face and the great weight of the mold, as a result of the plaster layer used in the conventional molding technique. It also allowed for proper ventilation and restrained any rundown of the irreversible hydrocolloid material proportioned to present greater fluidity and a better flow. Although statistically significant, the majority of the differences observed were restricted to tenths of millimeters. Minor values of this size are irrelevant in clinical situations, as the final sculpturing and adaptation of the facial prosthesis should necessarily be made directly on the patient's face during a clinical session.

The shorter working time and the greater comfort created by using the perforated thermoplastic custom mold evaluated in this study suggests that this technique should be employed for making facial prostheses. The slight dimensional alterations observed in the plaster casts are within the dimensional accuracy criteria required for making facial prostheses.

\section{References}

1. Ariani N, Visser A, van Oort RP, Kusdhany L, Rahardjo TBW, Krom BP et al. Current State of Craniofacial Prosthetic Rehabilitation. Int J Prosthodont. 2013; 26:57-67.

2. Veerareddy C, Nair C, Reddy R. Simplified technique for orbital prosthesis fabrication: a clinical report. J Prosthodont. 2012; 21: 561-8.

3. Rommerdale EH. Maxillofacial technology. 1., Part one. Introduction to facial impressions. Trends Tech Contemp Dent Lab. 1990; 7: 36-9.

4. Lemon JC, Okay DJ, Powers JM, Martin JW, Chambers S. Facial moulage: The effect of a retarder on compressive strength and working and setting times of irreversible hydrocolloid impression material. J Prosthet Dent. 2003; 90: 276-81.

5. Alsiyabi AS, Minsley GE. Facial moulage fabrication using a two-stage poly(vinyl siloxane) impression. J Prosthodont. 2006; 15: 195-7.

6. Holberg C, Schwenzer K, Mahaini L, Rudzki-Janson I. Accuracy of facial plaster casts. Angle Orthod.ont. 2006; 76: 605-11.

7. Siadat H, Mirfazaelian A. A handle for facial casts. J Prosthet Dent. 2003; 89: 323.

8. Shaikh SR, Patil PG, Puri S. A modified technique for retention of orbital prosthesis. Ind J Dent Res. 2011; 22: 863-5.

9. Ozcelick TB, Yilmaz B. Two-piece Impression Procedure for Implantretained Orbital Prostheses. Int J Oral Maxillofac Surg. 2012; 27: 93-5.

10. Al-Athel. The effect of selected variables on the retention of irreversible hydrocolloid impression material. J Contemp Dent Pract. 2008; 9: 57-64.

11. Littlefield TR, Cherney JC, Luisi JN, Beals SP, Kelly KM, Pomatto JK. Comparison of plaster casting with three-dimensional cranial imaging. Cleft Palate Craniofac J. 2005; 42: 157-64.
12. Holberg C, Schwenzer K, Mahaini L, Rudzki-Janson I. Accuracy of facial plaster casts. Angle Orthodont. 2006; 76: 605-11.

13. Marafon PG, Mattos BS, Sabóia AC, Noritomi PY. Dimensional accuracy of computer-aided design/computer-assisted manufactured orbital prostheses. Int J Prosthodont. 2010; 23: 271-6.

14. Farkas LG. Anthropometry of the head and face. 2nd ed. New York: Raven Press; 1994.

15. Politec Importação e Comércio Ltda.. Produto - Placa termoplástica Aquaplast - Sammons Preston Rolyan [cited 2013 Apr] Available from:. Accessible from http://www.politecsaude.com.br [April 10, 2013].

16. Sykes LM. Custom made ocular prostheses. A clinical report. J Prosthet Dent. 1996; 75: 1-3.

17. Rodrigues SB, Augusto CR, Leitune VC, Samuel SM, Collares FM. Influence of delayed pouring on irreversible hydrocolloid properties. Braz Oral Res. 2012; 26: 404-9. 